\title{
Fiziki Kayıpların Azaltılması İçin İzole Alt Bölgelerin Etkin Yönetimi
}

\author{
Recep Kılıç 1 $^{*}$ \\ ${ }^{1}$ Sakarya Su ve Kanalizasyon İdaresi (SASKİ), Kentpark, PK 144, Adapazari, Sakarya, TÜRKIYE (ORCID No:0000-0003-1580-1997) \\ recep.kilic@sakarya-saski.gov.tr
}

(İlk Geliş Tarihi Aralık 2020 ve Kabul Tarihi Ocak 2021)

(DOI: $10.31590 /$ ejosat.856200)

ATIF/REFERENCE: Kılıç, R. (2021). Fiziki Kayıpların Azaltılması İçin İzole Alt Bölgelerin Etkin Yönetimi, Avrupa Bilim ve Teknoloji Dergisi, (22), 306-315.

\section{Öz}

İçmesuyu şebekelerindeki su kayıpları en basit olarak şebekeye verilen su ile aboneden tahakkuk ettirilen su arasındaki fark olarak tanımlanmaktadır. Bu kayıpların pek çok sebepleri (sayaçların hatalı okuması, şebekedeki sızıntılar, depo sızıntı ve taşmaları ile pompa salmastralarından kaynaklanan kayıplar, vb.) vardır. Bu sebeplerden en önemlisi sistem basıncından kaynaklanan fiziki sızıntılardır. Bu sorunu çözebilmek için ileri otomasyon sistemleri ile izlemeyi içeren yeni yaklaşımlara ihtiyaç vardır. Bu izlemeyi en iyi şekilde yapabilmek için su dağıtım şebekeleri bilinen klasik yöntemden ziyade İzole Alt Bölgeler (İAB) şeklinde tesis edilmesi gerekmektedir. Su idareleri İAB'lerin girişlerine Basınç Kırıcı Vana (BKV) ve debimetre takarak sistem basıncını yönetmektedirler. Bu çalışmada, İAB'lerdeki BKV'lerin etkin bir şekilde çalıştırılması için yapılması gerekenlerden bahsedilmiştir. Ayrıca, İBA'ların verimli bir şekilde yönetilmesi için geliştirilen yazılımın saha uygulamasından örnekler verilmiştir. Geliştirilen yazılımın su yönetimine sağladığı katkılar ortaya konmuştur. Yazılım sayesinde şebekedeki fiziki sızıntı miktarları belirlenerek işletme verimliliği ortaya konulmuştur. Ayrıca İAB'ların etkin kontrolünün sonucu sağlanan kazanımlara örnekler verilmiştir. Çalışma sırasında İBA'ların basınçları 7.5 bardan 3-5 bara düşürülerek sistemin dengeli (stabil) çalışması sağlanmıştır. İAB'lerin etkin yönetilmesi sonucunda yüzeye çıkmayan arızalara zamanında müdahale edilmesinin sonucu olarak yaklaşık \% 7'lik su kaybının önlendiği ortaya konulmuştur. Ayrıca ortaya çıkan arıza sayılarında \%55'lik bir azalmanın olduğu görülmüştür.

Anahtar Kelimeler: Fiziki su kaybı, izole alt bölge, basınç yönetimi, su dağıtım sistemi

\section{Effective Management Of District Meters Areas To Reduce Physical Losses}

\begin{abstract}
Water losses in drinking water networks are simply defined as the difference between water supplied to the network and water accrued from the subscriber. There are many reasons (improper reading of meters, leaks in the network, tank leaks and overflows, as well as losses caused by pump seals, etc) for these losses. The most important of these reasons are physical leaks caused by system pressure. In order to solve this problem, new approaches are needed, which include advanced automation systems and monitoring. In order to make this monitoring in the best way, water distribution networks need to be created in the form of isolated District Meters Areas (DMA), rather than the conventionally known methods. Water administrations manage the system pressure by installing Pressure regulating Valves (PRV) and aflow meter at the inputs of DMAs. In this study, it is explained about what needs to be done to operate effectively PRVs in DMA. In addition, examples are given from the field application data treatments by means of the software developed for the efficient management of DMAs. The contributions of the developed software to water management have been demonstrated. The amount of physical leakage in the network is determined and operational efficiency is demonstrated through software. In addition, examples of gains are achieved as a result of effective control of DMAs. During the operation, the pressure of the DMAs is reduced from 7.5 bar to 3-5 bar, and the system was enabled to work stabally. As a result of effective management of IABS, water loss of approximately $7 \%$ is prevented by timely intervention in faults that do not surface. In addition, it was observed that there is a $55 \%$ decrease in the number of malfunctions.
\end{abstract}

Keywords: Water loss, district meters areas, pressure management, water distribution system

*Sorumlu Yazar: recep.kilic@sakarya-saski.gov.tr 


\section{Giriş}

Dünyanın birçok bölgesinde değişen iklim koşulları ve kuraklığın etkisinin artmasından dolayı su kayıplarının azaltılması ve kontrolü daha da önemli hale gelmiştir. Birçok su idaresi su kaynaklarının korumak için su kayıplarını ekonomik ve kabul edilebilir değere indirmede yeni stratejiler geliştirmektedir $(\mathrm{Wu}$, 2011).

Su kıtlığı probleminin çözümü geleneksel su kaynaklarının geliştirilmesi yönteminden küresel eğilim olan $\mathrm{Su}$ Talebi Yönetimine (STY) geçişte yatmaktadır. STY'yi açıklamak için birçok tanım kullanılmaktadır. En geniş anlamıyla, teknolojik olarak ölçüm ve düzenlemelerle (basınç kontrolü gibi) su talebinin kontrol edildiği; ekonomik, sosyal şartların göz önünde bulundurulduğu bir yaklaşım olarak ifade edilmektedir. Ekonomik yönü su fiyat tarifesini kapsamaktadır. Sosyal yönü ise su tüketiminde bilinçlendirme çalışmaları yapılarak abonelerin tasarrufa yönelik faaliyetlerde bulunmalarını sağlamaktır.

Su dağıtım sistemleri, en yüksek talepte en düşük basıncı karşılamak üzere tasarlanmaktadır. Ancak su dağıtım sistemlerinde gün boyunca değişken debi talepleri yaşanmasından dolayı, sistem basıncı da talebe bağlı olarak değişkenlik göstermektedir. Talebin düşük olduğu gün içerisinde belirli saatler ve gece sistem basıncı yükselmektedir (Choi Y.J., 2014). Talebin düşüp, basıncın yükseldiği anlarda, sistemdeki kaçak oranı da basınç artışına paralel olarak yükselmektedir. Böylelikle basıncın yüksek olduğu noktalarda, hem normal işletme şartlarında, hem de talebin düşük olduğu dönemlerde basıncın, ihtiyaç duyulan sabit minimum değere düşürülmesi gerekmektedir. Bu yüzden, şebekelerdeki su kaçaklarının azaltılması yönünde en önemli etken, basıncın değişken işletme şartlarında talebi karşılayacak değere düşürülerek kontrol altına alınmasıdır (Fernando G. A., 2019).

Su kaybının sıfır olduğu bir su dağıtım sistemi mevcut değildir. Su kayıpları ve şebekedeki sızıntıların bu günkü teknoloji ile tamamen önlenmesi imkânsızdır. Bir şehirde yaklaşık \% 10 oranında su kaybı normal sayılabilmektedir. Dünyadaki birçok büyük şehirde \% 50'ye ve hatta daha yüksek oranlara ulaşan su kayıpları olduğuna dair veriler bulunmaktadır (Karadirek, 2016). Türkiye'deki durumun dünyadakinden farklı olmadığ 1 bilinmektedir. Bununla birlikte, büyük ölçekli su şebekelerinin sorunsuz çalışmaması hala önemli bir mühendislik sorunudur (Ates, 2016). Bu sorunların başında ise su arıtma tesislerinde üretilen suyun son kullanıcılara ulaşmadan ekseriyetinin kaybolması işlenmiş suyun israf edilmesine ve su idarelerinin büyük gelir kayıplarına neden olmaktadır. Genellikle, su dağıtım sistemleri, daha önceden tahmin edilen büyüme oranıyla beraber genişletilmek üzere tasarlanır. Ancak, boru hatlarındaki öngörülemeyen hızlı yıpranma, uygulama hataları, hayat standardındaki ve nüfustaki artışa bağlı olarak taleplerin artışı, borulardaki basınç kayıplarının artışına neden olur (Hussein M., 2017).

Dünya üzerinde, su kaynaklarının hızla azalması karşısında mevcut sistemlerin en verimli şekilde kullanılması gerekmektedir. $\mathrm{Bu}$ yüzden, su sistemlerinde temel sorun olan kaçaklara karşı yeni teknolojileri kullanarak gerekli önlemlerin alınması zorunludur (Lambert, 2000).
Su kaçaklarının büyük ekonomik etkisi olduğundan, bu sorunla ilgili çeşitli yaklaşımlar önerilmiştir. Bununla birlikte, su kayıp problemlerini çözmede geleneksel yaklaşımlar yeterli gelmemektedir. Bu sorun ileri otomasyon sistemleri ile izlemeyi içeren yeni yaklaşımlarla çözülebilir (Abu-Mahfouz, 2016).

Şebekedeki kaçağı azaltmak için, su idareleri tarafından kullanılmak üzere bazı temel kaçak yönetim stratejileri önerilmiştir. Bu stratejiler Şekil 1'de görülmektedir. Burada basınç yönetiminin kaçak yönetim stratejisinin temel unsurlarından biri olduğu görülmektedir. Bunun nedeni, daha önceki araştırmaların sonucu olarak su dağıtım sistemindeki kaçak ve basınç arasında bir ilişkinin olduğunu ortaya koymasıdır (Thornton, Progress in practical prediction of pressure: Leakage, pressure: burst frequency and pressure: consumption relationships, 2005). Bu ilişki Denklem 1-2'de verilmiştir.

$$
q_{1}=k P^{n}
$$

Burada $q_{1}$ kaçak akış hızını, k kaçak katsayısını, $\mathrm{P}$ borudaki basınc1, $\mathrm{n}$ ise kaçak üssünü ifade etmektedir. Kaçak tipine bağlı olarak n değeri, 0.5 ila 2.5 arasında değişir (Abu-Mahfouz, 2016) (Lambert, 2000).

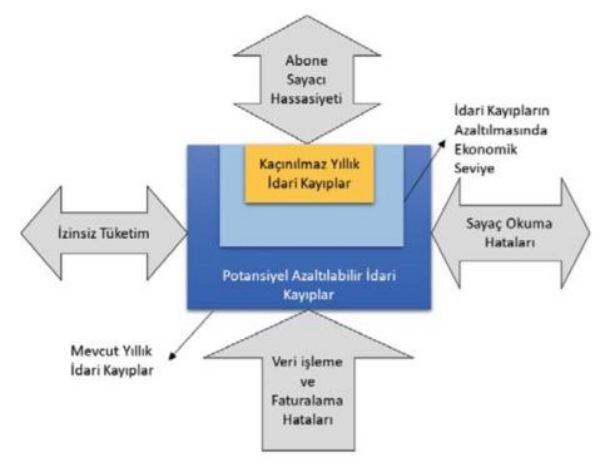

Şekil 1. Temel kaçak yönetimi stratejisi (Wu, 2011)

May (May, 1994) tarafından önerilen sabit alan ve değişken alan deşarjı (FAVAD) kavramına göre, sızıntı açıklıklarının boru uzunluğu boyunca değişmesine dayanmaktadır. $\mathrm{Bu}$ nedenle, kaçak-basınç ilişkisi ayrıca;

$Q_{1}=C_{d} A_{l}^{f} \sqrt{2 g H}+C_{d} A_{l}^{v} \sqrt{2 g H}$

şeklinde de yazılabilir. Burada;

$Q_{1}=\operatorname{Ak} 1$ Ş $\operatorname{Hizı}(\mathrm{m} / \mathrm{s})$

$C_{d} \mathrm{v}=$ Kaçak deşarj katsayısı

$A_{l}^{f}$ Sabit kaçak açıklığı alanı $\left(\mathrm{mm}^{2}\right)$

$A_{l}^{v}=$ Değişken kaçak açıklık alanı $\left(\mathrm{mm}^{2}\right)$

$\mathrm{H}=$ Pompa basinc1 $(\mathrm{mSS})$

$\mathrm{g}=$ Yer çekimi ivmesi $\left(\mathrm{m} / \mathrm{s}^{2}\right)$

Her iki denklemde de, şebeke basıncının düşmesiyle kaçak akış hızının da düşeceği görülmektedir. $\mathrm{Bu}$ nedenle, Su Dağıtım Sistemlerinde (SDS) basınç yönetimi stratejisi, sızıntıları azaltmak için en verimli ve uygun maliyetli politikalardan biri olarak kabul edilmektedir (Giustolisi, 2008). (SDS)'lerde sızıntıları en aza indirmenin yanı sıra, boru patlama risklerini azaltmak için basınç yönetiminden yararlanabilir. Bu durum ise sistemin hizmet ömrünü uzatır. (Farley, 2003) (Thornton J. L., 2007). 
$\mathrm{Su}$ dağıtım şebekelerindeki su basıncının düzenlenmesi, genellikle karmaşık şebekelerin, izole alt bölgelere (İAB) bölünmesiyle elde edilir (Farley, 2003) (Araujo, 2006). Su dağıtım şebekesini izole alt bölgelere bölerek yönetilebilir hale getirmek için, belli kriterler göz önüne alınır. Bu kriterler, bölge içinde kalan abone sayısı, bölge içinde kalan şebeke uzunluğu, o bölgenin topografyası vb. gibi değerlerdir [ (Muhammetoğlu A, 2018)]. İzole bölgeler oluşturulduktan sonra, izole bölgenin giriş noktasında hem ölçüm için hem de kontrol elemanlarının montajı için kontrol odaları mevcuttur (Karathanasia I, 2016).

Bu İAB'ler su dağıtım şebekesinde birden fazla bulunmaktadır (Kanakoudis V., 2014). Bu yüzden İAB'lerin etkin bir şekilde kontrol edilmesi ve izlenmesi önem arz etmektedir [ (Kara S., 2015) (Fontana N., 2018). Her bir İAB bölgesi anlık olarak takip edilmelidir. İAB girişindeki kontrol odasında bulunan bütün donanımlar gerçek zamanlı olarak kontrol edilebilmelidir. Basınç yönetimi için kullanılan BKV'lerin çıkış basınç değerleri abone kullanım konforunu etkilemeyecek şekilde kontrol edilmelidir (Samir N., 2017). Her bir İAB'nin minimum akış değerleri, ortalama akış değerleri ve su kayıp oranları anlık olarak izlenmelidir (García V. J. Cabrera E., August 2006). Sistemin set değerleri dışındaki herhangi bir değişiklik kullanıcı ekranına veya yetkili kullanıcının bilgisayar ekranına uyarı olarak yansımalıdır.

Bu çalışmada İAB leri için geliştirilen yazılımla;

- Sistem kesintisiz izlenecektir,

- Sistemde oluşan herhangibir anormallik ilgili kişisine mesaj veya mail yoluyla bildirilecektir,

- Sistem üzerindeki değişiklikler web üzerinden yapılabilecektir,

- Su kayıplarının yönetilmesinde en önemli parametre olan min. gece debisi izlenebilecektir,

- Sisteme verilen su anlık olarak görülebilecektir,

- İzole Alt Bölgelerin kayıp oranları anlık olarak izlenebilmektedir,

- Sistemle ilgili karşılaştırmalar,

yapılabilmektedir. Çalışmada, İAB'lerin yönetiminde bu yazılımın sağladığı faydaların çıtılarından bahsedilmektedir. Sağlanan faydalara sahadan örnekler verilerek sistemin performansı gösterilmektedir.

\section{2 . Su Dağıtım Şebekesi}

Şekil 2' de görüldüğü gibi bir su dağıtım sistemi (SDS), her birinin uzunluk, çap ve sürtünme direnci katsayısı gibi özellikleri tanımlanmış bir dizi birbirine bağlı borulardan meydana gelir. Her bir boru, su akışının şebekeye girdiği veya şebekeden çıtığı bir tüketim noktasında (talep) kesişir. Bu nokta bir kavşak düğümü olarak adlandırılır. Her boru, pompalar, bağlantı parçaları ve vanalar gibi sistem elemanları da içerebilirler. Pompalar, yeterli basınçta abone talebini karşılamak için veya iletim amacı ile kullanılır. Ayrıca, SDS sistemdeki basıncı sürekli sabit tutan bir depoya da sahip olabilir. SDS'lerin tasarımında, hidrolik modeller, sistem parametrelerinin planlanması ve yönetimi kritik bir rol oynamaktadır.

SDS'lerde kayıplar tahmin edilemezler. $\mathrm{Bu}$ kayıplar düğüm noktalarında ve borulardaki sızıntı nedeniyle meydana gelebilir. SDS'deki kaçakları azaltmak için su idareleri tarafindan kullanılmak üzere bazı temel kaçak yönetim stratejileri önerilmiştir (Wu, 2011). Bu stratejiler Şekil 2'de görülmektedir.

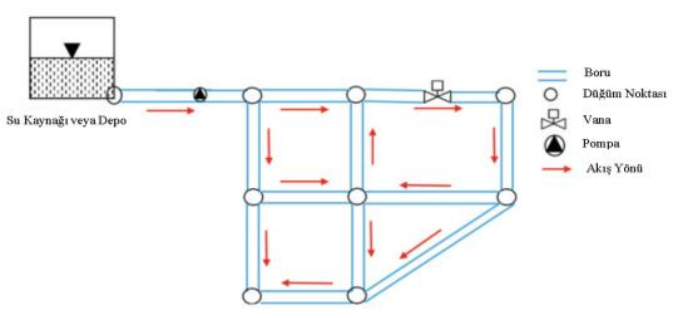

Şekil 2. Su dă̆ıtım şebekesi şeması

\section{Su Dağıtım Sistemlerinin İzole Alt Bölgelere Ayrilmasi}

Büyük bir SDS'de su kayıplarını yönetmek, zordur. Su kayıplarını etkin bir şekilde yönetmek büyük bir SDS'ini İAB adı verilen daha küçük izole alanlara bölmek kabul görmüş bir yaklaşımdır. Şekil 3 'te her İAB'de debi miktarı ile basıncının izlenip kontrol edilebildiği bir konumdan su verildiği görülmektedir. Bu sayede her bir İAB'deki su kayıp oranları kolaylıkla hesaplanabilir ve yönetim önlemleri etkili bir şekilde uygulanabilir (Jaber M. A. Alkasseh, 2013).

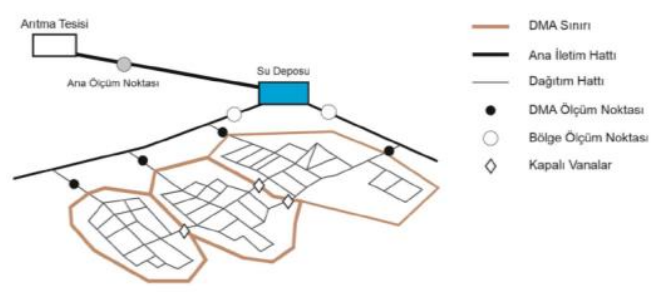

Şekil 3. Su Dağıtım Sisteminin İzole Alt Bölge
Şeması

İzole bölgeler ortaya çıkarıldıktan sonra, izole bölgenin giriş noktasına hem ölçüm hem de kontrol elemanlarının montajı için yer altına bir oda inşa edilmiştir. Bu oda içinde ölçüm amaçlı bir sayaç (elektromanyetik debimetre, ultrasonik debimetre, Woltman tipi sayaç vs.), basıncı yönetmek amacı ile BKV (piston tipi veya y tipi) giriş-çıkış vanaları, şebekenin içine herhangi bir yabancı madde kaçmaması için pislik tutucu, bölge içine gönderilen suyun içindeki hava kabarcıklarını almak için çift küreli vantuz teçhiz edilmiştir, Şekil 4'de İAB odasına ait donanımlar gösterilmektedir.

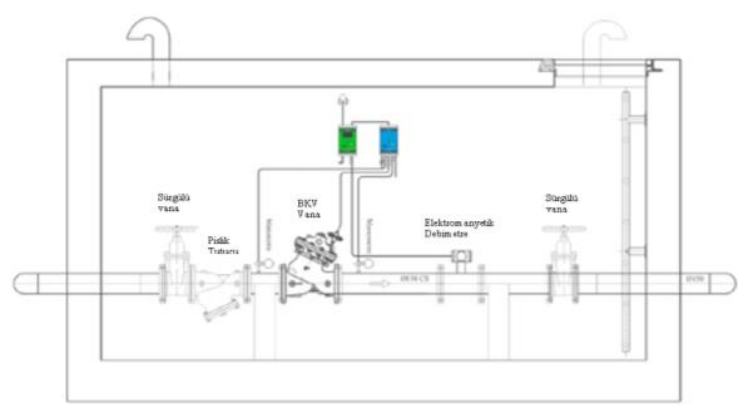

Şekil 4. Izole Alt Bölge (İAB) Giriş Kontrol Odası 
İAB odaları tasarlanırken kullanılacak donanımların teknik olarak seçimi çok önemlidir. Örneğin, bu noktadaki debi ölçümü çok hassas olmalıdır. $\mathrm{Bu}$ sebeple harici enerji kaynaklı elektromanyetik debimetre tercih edilmelidir.

Kullanılacak basınç kırıcı vanaların seçimini yaparken, basınç kırıcı vananın, ne kadar ve hangi oranda basıncı düşüreceği belirlenmeli, bununla beraber bölgeye verilecek debi miktarı hesaplanmalı ve bu kriterler doğrultusunda basınç kırıcı vana seçilmelidir. Her basınç kırıcı vana kontrol edilirken farklı karakteristikler göstermektedir. Bu nedenle, basınç kırıcı vananın kendi kapalı devre kontrolü iyi olmalıdır. $\mathrm{Bu}$ odanın önemli parçalarından bir tanesi de elektronik BKV kontrolörüdür. Kontrolör sayesinde bölgenin basıncı otomatik olarak ayarlanırken, aynı zamanda oda içindeki sistemlerden ve cihazlardan alınan veriler anlık olarak bir merkeze transfer edilmektedir. Cihaz tasarlandığı konfigürasyona göre bölgeye gönderilen suyun basıncını ayarlamakta ve konfigürasyonda belirtildiği şekilde verileri merkeze transfer etmektedir.

\section{Gerçek Zamanlı Kontrol (GZK) Algoritması}

İzole Bölgeler tespit edilmiş, İAB girişine oda yapılmış, gerekli kontrol ve ölçüm ekipmanlarının montajı yapılmıştır. Bundan sonraki adım artık bölge basıncının yönetilmesini sağlamaktır. İçmesuyu şebekelerinde, sistem ihtiyacından daha fazla basınçla çalıştırıldığında mevcut kayıp noktalarından daha fazla su kaybedildiği yapılan hesaplamalar sonucunda görülmüştür. $\mathrm{Bu}$ problemin çözümü için bölgeye verilen su basıncının belli yöntemlerle ayarlaması yapılmalıdır. İAB'de basınç yönetimi yapacağımız BKV akışa duyarlı çalışacak şekilde gerçek zamanlı kontrol (GZK) edilecek şekilde tasarlanmıştır. Debimetreden alınan akış verisine göre kontrol olayını gerçekleştirecek algoritma geliştirilmiştir. Sistem ayarlanırken bölgenin su kullanım verilerine göre bir basınç debi tablosu yapılmıştır. $\mathrm{Bu}$ tablo kontrolöre BKV ayar parametresi olarak yüklenmiştir. Sisteme basınç tablosu girildikten sonra sistem debimetreden aldığı akış verisine göre çıkış basıncını ayarlamaktadır. $\mathrm{Bu}$ yöntemin diğer basınç kontrol yöntemlerine göre faydası, su tüketim grafiğine göre çıkış basıncının ayarlanmasıdır. Bu yöntem sayesinde gün içinde ihtiyaç duyulan debi talebinin artışında veya düşmesinde en uygun çıkış basınç değerini gerçek zamanlı olarak ayarlayacaktır. İAB odalarındaki tüm cihazlar GZK olarak ayarlanmıştır. Ayrıca BKV'nin kontrol modları olan sabit basınç kontrolü, zaman modülasyonlu basınç kontrolü ve akış modülasyonlu basınç kontrolü, uzaktan GZK olarak ayarlanabilmektedir. Bütün bu işlemler kullanıcı ofisinden yapılabilmektedir. Bu işlemlerin kolay bir şekilde yapılabilmesi için web tabanlı bir yazılım tasarlanmıştır. Şekil 5'te gerçek zamanlı kontrol algoritması gösterilmektedir.

\section{Yönetim ve Raporlama Yazılımı}

İzole Alt Bölgelerin (İAB) verimli bir şekilde yönetilmesi için web tabanlı bir yazılım geliştirilmiştir. Geliştirilen bu yazılımla kullanıc1 ister cihaz üzerinden isterse uzaktan web yönetim yazılımından cihazın kontrol yöntemini seçebilir, (Şekil 6). Cihazın içindeki kontrol yöntemlerinden biri seçildikten sonra seçilen kontrol yönteminin prosedürleri uygulanır. Seçilen kontrol yöntemi sabit basınç kontrol yöntemi ise sistem sabit basınç set değerini referans alır. Sabit basınç set değeri cihaz üzerinden girilebildiği gibi yine uzaktan web yönetim yazılımı ile de girilebilir. Bu değer vana çıkışında görülmek istenilen değerdir. Eğer kontrol yöntemlerinden tarifeli basınç yönetimi seçilmişse, öncelikle zaman basınç tablosu doldurulur (Şekil 7).

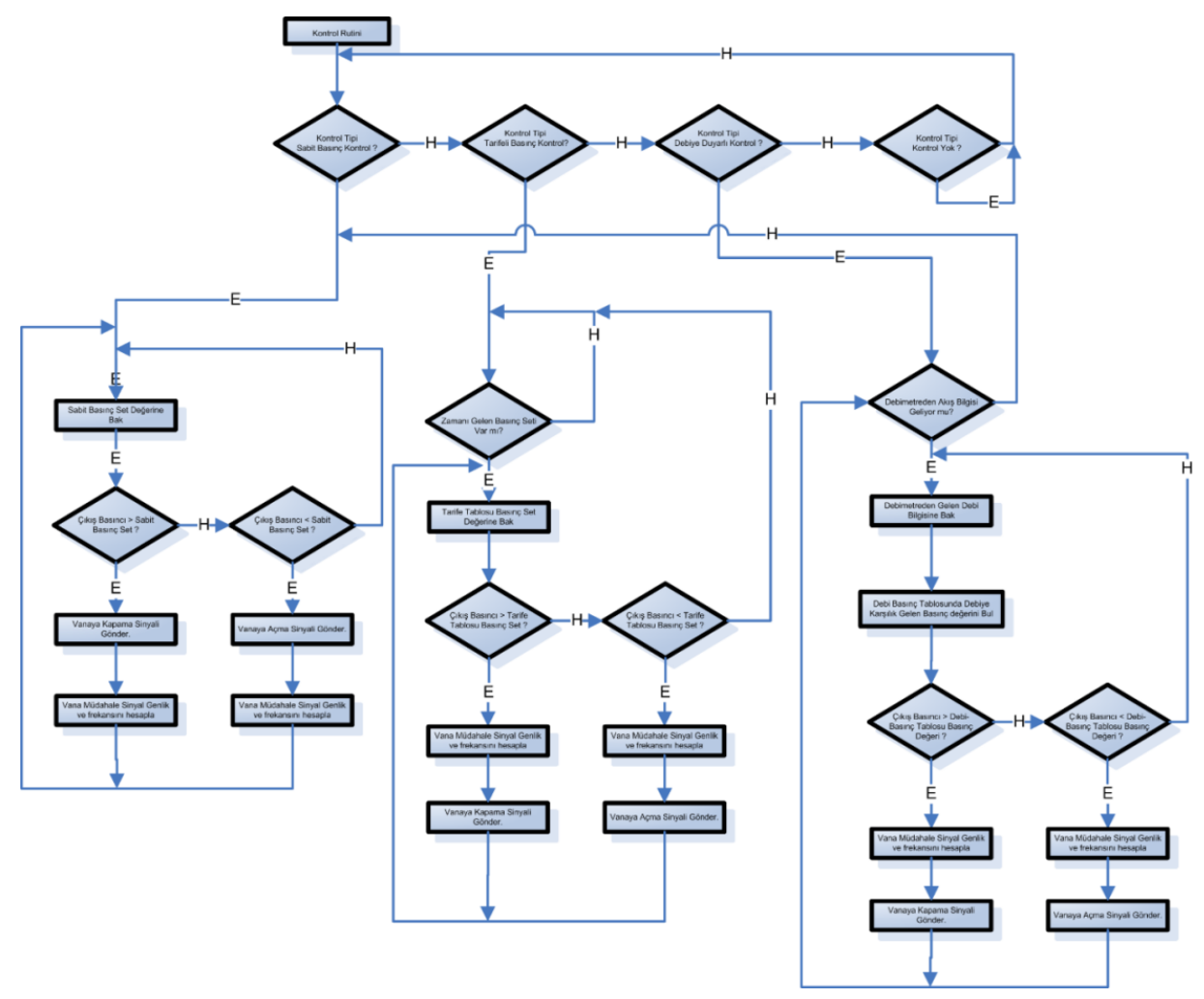

Şekil 5. Gerçek Zamanlı Kontrol Algoritması 


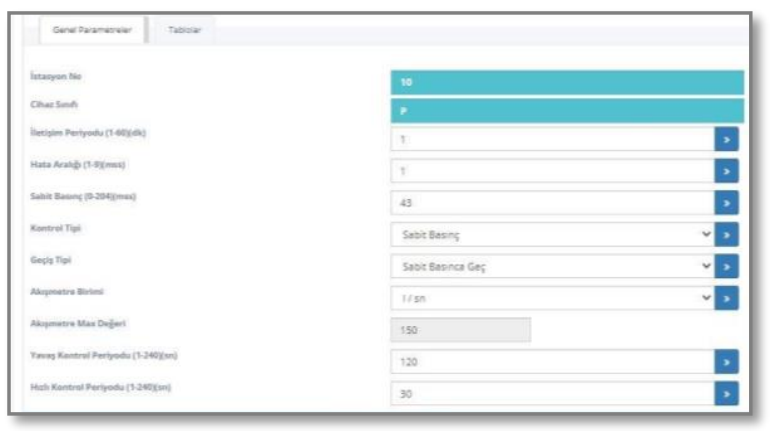

Şekil 6. BKV cihazının kontrol yöntemini Seçim ekrant

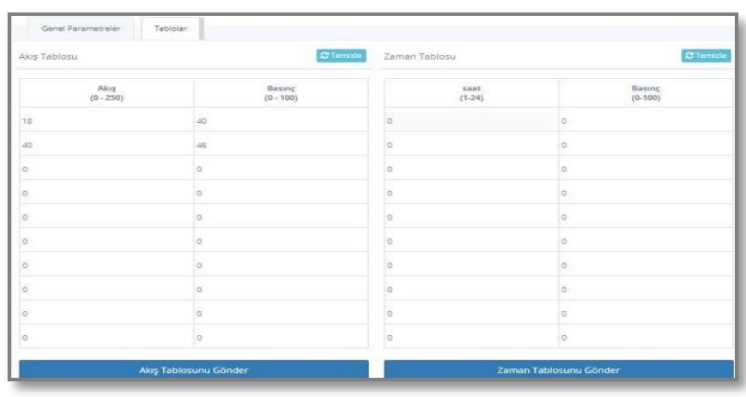

Şekil 7. Tarifeli basınç yönetimi durumunda zaman basınç tablosu doldurma ekranı

$\mathrm{Bu}$ tablo cihaz üzerinden değiştirilebildiği gibi web yönetim yazılımı üzerinden de değiştirilebilir. Gün içinde 10 farklı zaman için basınç set değeri girilebilir. Kontrol yöntemlerinden debiye duyarlı kontrol seçilmişse, cihaz üzerinde debi basınç tablosu doldurulur (Şekil 7). Bu tablo kontrolöre BKV ayar parametresi olarak yüklenmiştir. Tablo web yönetim sistemi ile de uzaktan doldurulup cihaza gönderilebilir. Tabloda istenilen debi aralığında çıkış basıncının değeri belirlenir. Debi bilgisi sistemde bulunan debimetreden alınır. Alınan akış verisine göre çıkış basıncı ayarlanmasında dolayı, sisteme kesintisiz debi bilgisinin gelmesi gerekir. Debi bilgisinin kesildiği durumlarda sistemin kesintiye uğramaması için diğer kontrol yöntemlerinden birine otomatik geçiş sağlanır. Bu sebepten dolayı debi bilgisinin geldiğinden kesinlikle sistemin emin olması gerekir. Gelen debi bilgisine göre belirlenen basınç set değerinin yakalanması için kontrol prosedürleri uygulanır. Vananın açması ve kapaması için gerekli sinyaller vananın pilotunu kumanda eden aktüatöre gönderilir. Bu döngü kontrol tipi değişene kadar devam eder. $\mathrm{Bu}$ yöntemle diğer kontrol yöntemlerine göre daha esnek çıkış basıncı ayarı tayin edilmektedir. Gün içinde ihtiyaç duyulan debi talebinin artışında veya düşmesinde en uygun basınç değeri ne ise çıkış basıncı o olacak şekilde sistem kendisini gerçek zamanlı olarak ayarlayacaktır.

Yönetim ve raporlama yazılımı vasitası ile İAB odalarında bulunan tüm cihazların, uzaktan ayarlanması ve raporlanması yapılabilmektedir. Kontrolörlerin birçok ayarı sahaya gitmeden uzaktan gerçek zamanlı ayarlayabilmeleri mümkündür.
Yazılım da işlemler kullanıcı bazlı kayıt altına alınmakta ve raporlanmaktadır. Herhangi bir İAB noktasında ayar değişikliği kimin tarafından yapıldı ̆̆ hangi tarih ve saatte yapıldığı kayıt altına alınmaktadır (Şekil 8)

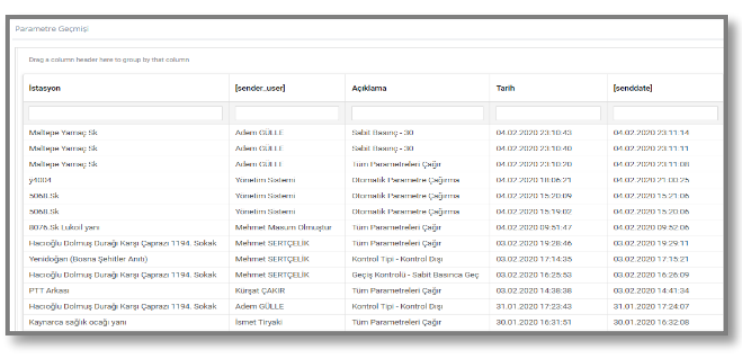

Şekil 8. İAB ayar değiş̧iklikleri görüntü ekranı

İstenilen İAB'lere ait geçmişe yönelik giriş basınc1, çıkış basıncı, debi verileri analiz edilmek üzere istenildiği anda raporlanabilmektedir (Şekil 9).

Cihazlar kurulup ayarları yapıldıktan sonra web yazılımı üzerinden sürekli İAB izlemeye gerek yoktur. Yazılım dâhilinde bulunan alarm menüsü kullanılarak takip edilmesi gereken ve kritik öneme sahip İAB'ler için alarmlar tanımlanabilmektedir (Şekil 10). Sistem bu alarm seviyelerini geçtiğinde tanımlı kişilere sistem tarafından otomatik mail veya mesaj gönderilerek bilgilendirme yapılabilmektedir (Şekil 11).

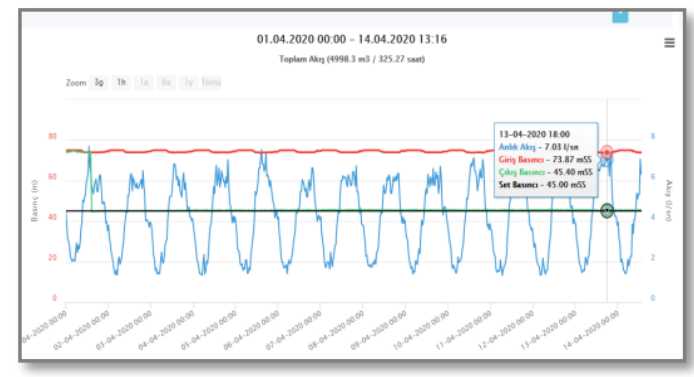

Şekil 9. IAB 'lere ait geçmişe yönelik giriş basıncı, çıkış basıncı, set basıncı ve debi verileri raporlama ekranı

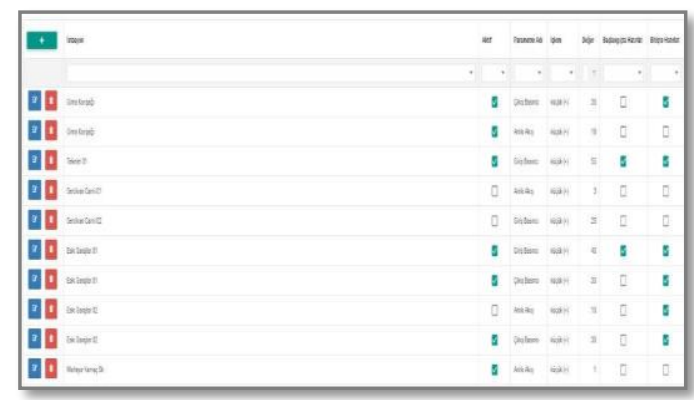

Şekil 10 IBA 'ların alarm tanımlama ekranı 
Ayrıca programdan istenilen tarihler arasında verilen toplam su miktarı değerleri alınabilmektedir. Yine anlık olarak sistemin akış bilgisi, giriş basıncı, çıkış basıncı ve set basıncı değerleri takip edilebilmektedir (Şekil 9). İAB'lerdeki maksimum akış ortalaması ve minimum akış ortalaması takip edilerek grafikte değişim gözlemlenebilmektedir (Şekil 12).

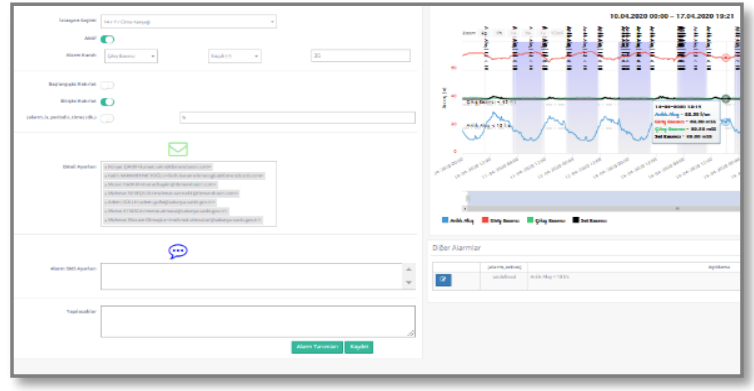

Şekil 11. Alarm ekran görüntüsü

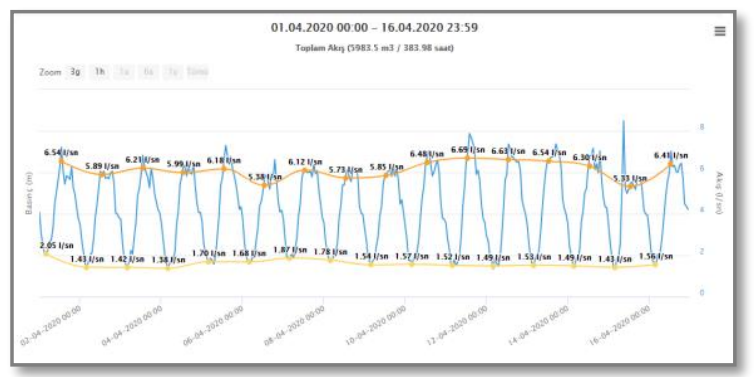

Şekil 12. IBA'ların maksimum ve minimum akış ortalamast

Her bölgeye ait fiziki kayıp oranı görülebilmektedir. $\mathrm{Bu}$ sayede kayıp oranı yüksek olan bölgeler tespit edilerek kayıp önleme çalışmaları bu bölgelerde yoğunlaştırılmaktadır (Şekil 13). Yazılım vasıtasıyla grafik karşılaştırma ile aynı istasyona ait farklı tarihlerde ya da farklı istasyonların istenilen tarihlerdeki anlık akış, giriş basıncı ve çıkış basıncı bilgileri karşılaştırma yapılabilmektedir (Şekil 14). $\mathrm{Bu}$ sayede aynı İAB'lerin farklı yıllarda aynı dönemleri karşılaştırılarak kayıp ile mücadele en verimli bir şekilde yapılabilmektedir.

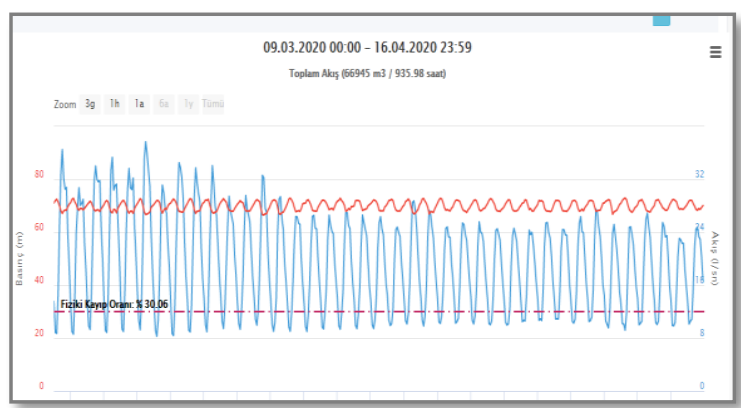

Şekil 13. IBA'ların fiziki kayıp ortalaması

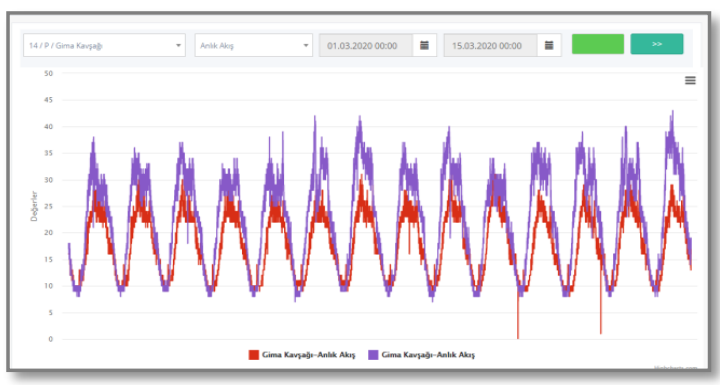

\section{Şekil 14. IBA'lardaki akış ve basınç bilgilerini karşılaştırma ekranı}

\section{Vaka Çalışması}

$\mathrm{Bu}$ çalışma Sakarya ili merkezinde (Adapazarı, Serdivan ve Erenler) yapılmıştır. Bölgenin $\mathrm{Su}$ Dağıtım Sistemi (SDS) kayıp-kaçak ile etkin mücadele edebilmek adına 111 adet İzole Alt Bölgeye (İAB) ayrılmıştır. Devreye alınan İAB sayısı 49 adettir.

Tüm İAB'ler gerçek zamanlı kontrol edilmekte olup geliştirilmiş web tabanlı program vasıtası ile izlenmektedir. Bu program aktif olarak çalıștırılmaya başlanmıştır. Çalışma sahasının yaklaşık nüfusu 374,801 ve abone say1s1 155,874 'dir. Kontrol edilen su dağıtım sistemindeki ana boruların toplam uzunluğu yaklaşık 1,750 km'dir. Nominal Çaplar $\phi 1000 \mathrm{~mm}$ ile $63 \mathrm{~mm}$ arasında değişmektedir. Hizmet verilen alanı besleyen depoların kotu 104 m, ağırlıklı yerleşke ise $32 \mathrm{~m}$ kodlarındadır. Sistemin çalışma basinc1 7.5 bar $(75 \mathrm{~m})$ dir.

\section{Sonuç Ve Öneriler}

Literatürdeki kriterlere uygun bir şekilde SDS'leri İAB'lere ayrıldıktan sonra, İAB'lerin girişine yapılan kontrol odaları öncelikle manuel olarak test edilirler. $\mathrm{Bu}$ testler sonucunda her hangi bir problem gözükmezse İAB'lerin sistem tanımlamaları yapılır. $\mathrm{Bu}$ sistem tanımlamaları programın daha rahat ve kolay yönetilebilmesi için ilçe bazında sisteme kaydedilmektedir. Bu kayitlar sonucunda sistemin ekran görüntüsü Şekil 15'de görülmektedir. Burada sol bölmede programın kullanım ikonları yer almakta, üst bölmede tanımlı ilçeler yer almakta ve ana ekranda ise seçili ilçedeki istasyonları küçük kareler şeklinde göstermektedir. 


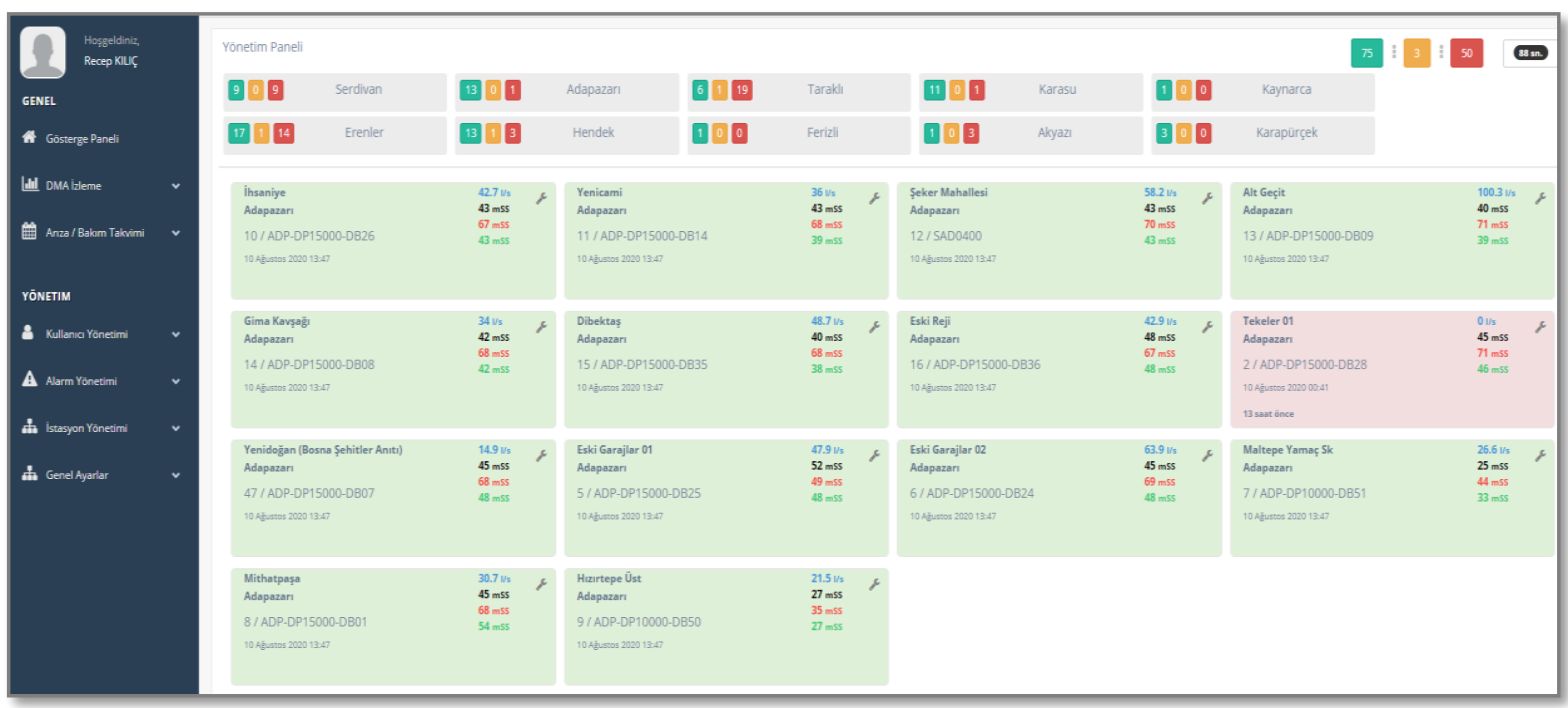

\section{Şekil 15. WEB Programinin Ana Ekran Görüntüsü}

İAB'lerin etkin bir şekilde yönetilmesi için geliştirilen programın aktif bir şekilde kullanılması gerekmektedir. Bu program sayesinde kurumsal olarak pek çok fayda sağlanmıştır. Ortaya çıkan birçok arızaya zamanında ve etkin bir şekilde müdahale edilmiştir. Yüzeye çıkmayan birçok su arızaları sistemden fark edilerek akustik dinleme yöntemleriyle noktasal olarak yeri tespit edilmiş ve onarılmıştır. Bölgedeki arıza durumuna bağlı olarak sisteme verilen sudaki artış net olarak gözlemlenebilmektedir. Bu sayede gerekli tedbirler alınarak arızanın hızlı bir şekilde bulunması sağlanmaktadır. Bu durum yüzeye çıkmayan arızalar için bazen günlerce sürdüğü gözlemlenmektedir.

Sistem devreye ilk alındığında her bir İAB'ler izlenmekte sistemin giriş debisi ve kritik nokta basınç ayarları abonelerin kullanım konforunu bozmayacak şekilde ayarlamaları yapılmaktadır. Bu ayarlamalar yapıldıktan sonra bütün bölge bir program çerçevesinde akustik dinlemeden geçirilmektedir. Dinleme sırasında yüzeye çıkmayan arızalar tespit edilmektedir.

Çalışmanın yapıldığı alanlardan biri olan Hızırtepe bölgesi Adapazarı ilçe merkezinde yaklaşık 1871 abonesi olan, konut ağırlıklı ve azda olsa işyerleri bulunmaktadır. Bölgenin alt yapısı 1999 depreminin hemen sonrasında acil olarak yapılmış daha sonra her hangi bir yenileme çalışması yapılmamıştır. Bu sebepten ötürü bölgenin su kayıp oranı oldukça yüksektir. Su kayıpları ile mücadelede minimum gece debisi en önemli parametrelerden birisidir. $\mathrm{Bu}$ sebeple çalışmamızda bu parametre bize daima yol gösterici olacaktır. Bölgenin devreye alınmasından sonra ortalama min. gece debisi 34-35 1/sn olarak gözükmektedir. Bölgenin gerek akustik dinleme gerekse alan daraltma yönte mleri ile elden geçirilmesinden sonra ortalama min gece debisinin 6-7 1/sn olduğu Şekil 16'da görülmektedir. Çalışma sonucunda ortalama kazanç 29.2 1/sn olarak elde edilmiştir (Şekil16). Bölgenin su tüketimine ve min. gece debisine geniş zaman aralığında (01.01.2019-31.07.2020) baktı̆̆ımızda da min gece debisinin 6-8 1/sn aralığında olduğunu görmekteyiz (Şekill7). Bunun dışındaki yükselmeler arıza kaynaklı olmaktadır.

Ayrıca Şekil 17'de min gece debisinin anlık akış grafiği sarı renkli görülmektedir. Bu şekilde 01.05.2019-01.06.2019 tarihleri ve 01.05.2020-01.06.2020 tarihleri aralığındaki gece debisinde yükselme olmasının sebebi Ramazan Ayı'ndaki gece kullanımlarından kaynaklanmaktadır. Buradan da şu ortaya e-ISSN: 2148-2683 çıkmaktadır ki literatürdeki min. gece debisi hesaplama teorisine ( (García V. J. Cabrera E., August 2006) (Jaber M. A. Alkasseh, 2013)) Ramazan ayındaki su tüketim davranışı uymamaktadır.

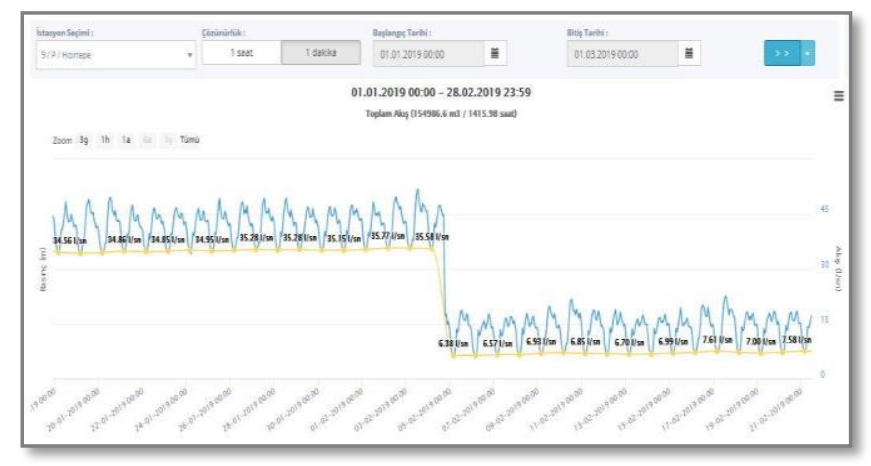

Şekil 16. Hozırtepe bölgesinin minimum gece Debisinin belirlenmesi

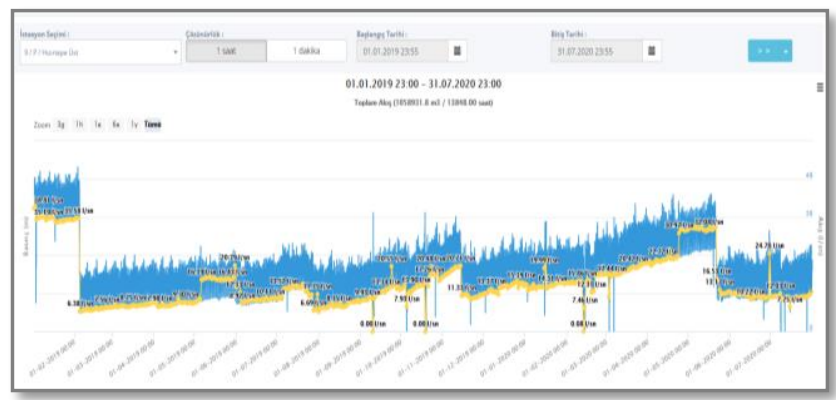

Şekil 17. Huzırtepe bölgesi su tüketim ve min gece debisi değişiminin geniş aralık bandindan izlenmesi

Su kaybı ile mücadelede İAB'lerin büyüklüğü çalışmanın verimliliği açısından büyük önem arz etmektedir. Bu nedenle İAB'nin abone sayısı 3000 olacak şekilde ayarlanması birçok çalışmada belirtilmektedir (Kazeem B. A., 2018) (Muhammetoğlu A., 2018). Aşağıda örnek vereceğimiz bölgede henüz küçük İAB'lere ayrılmamış bir bölgedir. Bu yüzden bölgede arıza tespitinin yapılması oldukça zor olmaktadır. Şekil 18 'de arızanın ortaya çıkması ile bulunması arasında yaklaşık iki haftalık bir sürecin olduğu görülmektedir. Yine Şekil 18'den min gece debisinin 29 l/sn'ler den 69 l/sn ye yükseldiği görülmektedir. 
Şekil 19'da ise Yazlık bölgesinin geniş band aralığındaki min gece akışı ile anlık su tüketimi grafiği görülmektedir. Şekilden de görüleceği gibi bölgenin ortalama min gece debisinin yaklaşık olarak 25-30 1/sn olduğu görülmektedir. Bunun üzerindeki debilerin kayıp olacağı aşikardır.

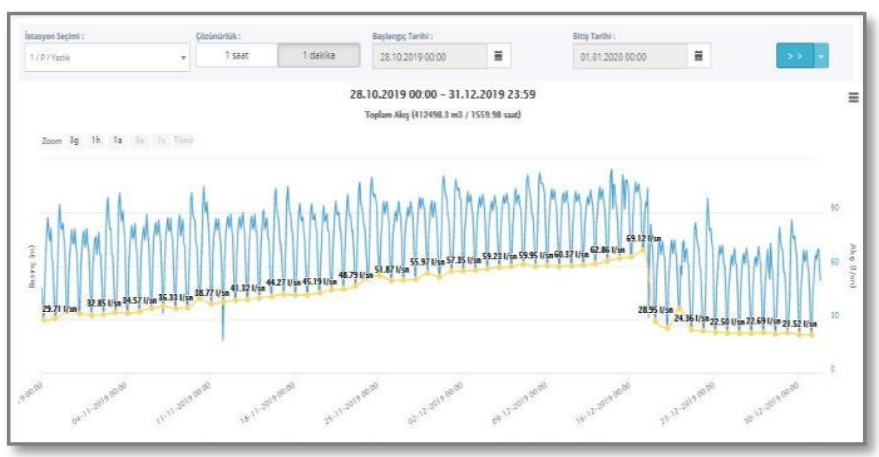

Şekil 18. Yazlık bölgesi arıza oluşum grafiği

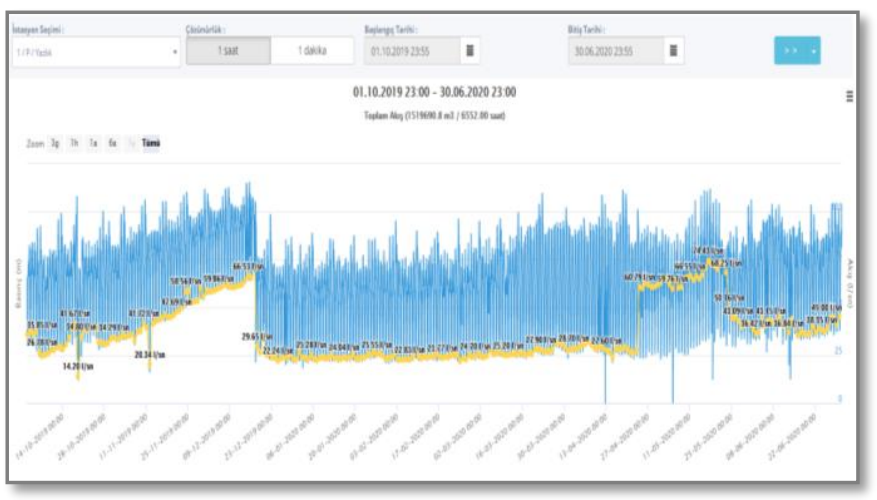

Şekil 19. Yazlık bölgesi su tüketim ve min gece debisi değişiminin geniş aralık bandından izlenmesi

Aşağıdaki verilerin alındığı bölge Adapazarı ilçe merkezinde yaklaşık 2,266 abonesi olan, konut ve işyerleri bulunmaktadır. Bölgenin alt yapısı 1999 depreminin hemen sonrasında acil olarak yapılmış daha sonra her hangi bir yenileme çalışması yapılmamıştır. Bu sebepten ötürü bölgenin su kayıp oranı oldukça yüksektir. Şekil 20'de görülebileceği gibi çalışma öncesinde bölgenin ortalama minimum gece debisi 20-21 1/sn arasında gözükmektedir. Akustik dinleme sonrasında bulunan arızanın giderilmesi sonucu bölgenin min. gece debisi $8-9$ 1/sn olmaktadır. Tespit edilen bir arıanın giderilmesi sonucu kazanılan su miktarı ise $11.93 \mathrm{l} / \mathrm{sn}$ dir. Min. gece debisindeki küçük salınımlar vatandaş kullanımına ve yüzeye çıkan arızalarla ilgilidir (Şekil20).

Şekil 21'de ise bölgenin geniş band aralığındaki min. gece debisi ve anlık akış grafiği görülmektedir. Grafikten de görüleceği gibi min. gece debisi sürekli yükselmekte ve uzun süre bu şekilde devam edilmektedir. Bu olayın sebebi bu bölgenin merkezde olması ve bulunan arızaların hemen yapilamamasından kaynaklanmaktadır. $\mathrm{Bu}$ tür bölgelerde yapılması gereken en uygun yöntem bölgenin alt yapısının değiştirilmesidir.

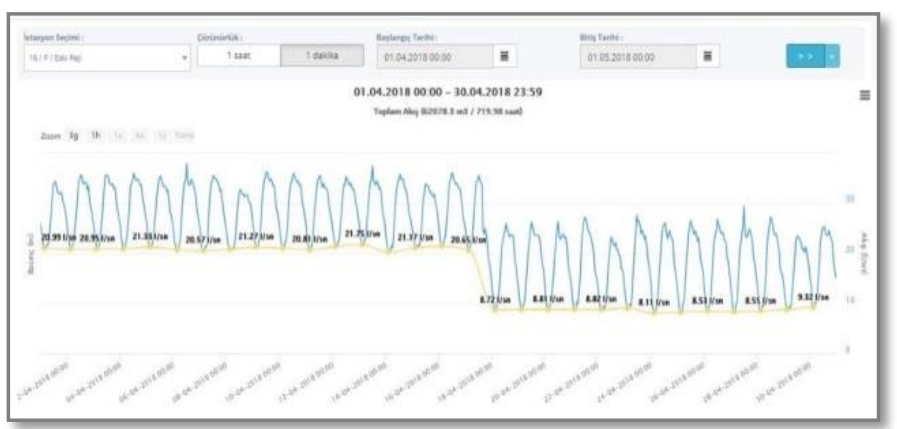

Şekil 20. Eski Reji bölgesinin minimum gece Debisinin belirlenmesi

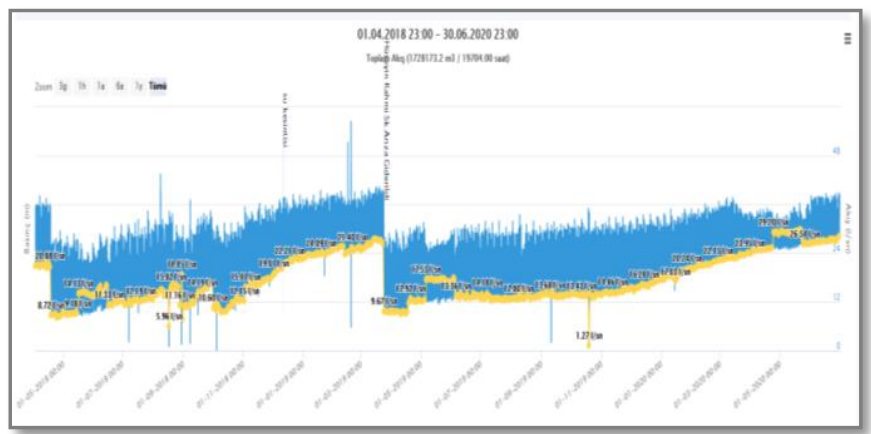

Şekil 21. Eski Reji bölgesi su tüketim ve min gece debisi değişiminin geniş aralık bandından izlenmesi

Bu yazılımın İAB'ler ile etkin bir şekilde kullanılmasından sonra su kayıplarının önlenmesi adına belli başlı faydalar elde edilmiştir. Bunlardan en önemlisi yapılan her bir İAB'nin kayıp oranını program aracılığı ile takip edilmesidir. Yine her bir İAB'nin max. ve min. akış ortalaması ve ortalama debinin anlık olarak izlenebilmesidir. Ayrıca bütün İAB'lerin değerlerini karşılaştırma yapacak şekilde grafikleştirerek kayıpların önlenmesinde hangi bölgelere öncelik verileceği hususunda büyük kolaylık sağlamaktadır (Şekil 22).

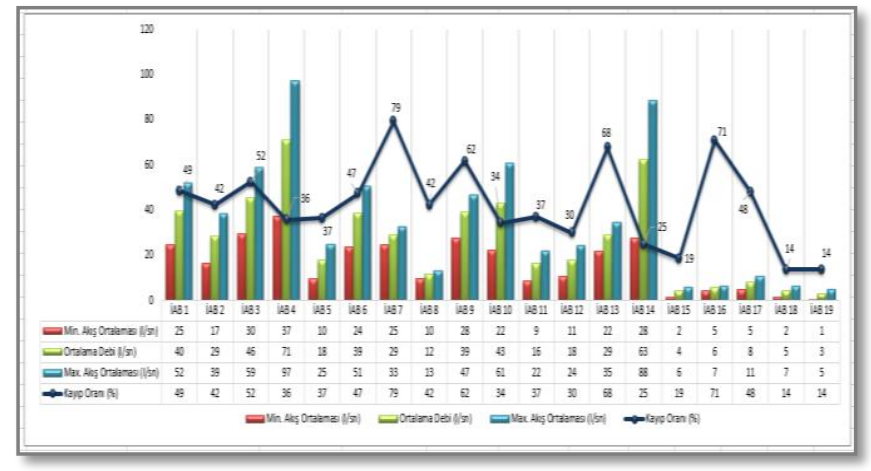

Şekil 22. IAB'lerin max. ve min. akış ortalaması, ortalama debi ve su kayıp oranlarl grafiği 


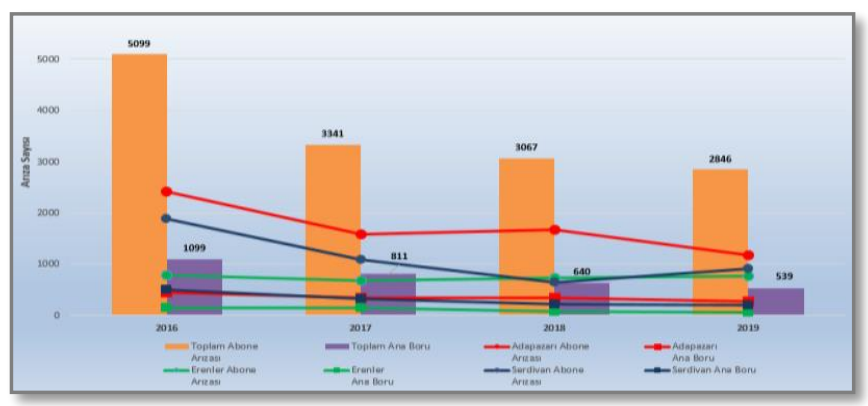

Şekil 23. Çalışma sonucu elde edilen arıza sayıları grafiği

İzole Alt bölgelerin etkin yönetiminin sonucunda sağlanan faydalardan bir diğeri ise arıza sayılarındaki azalmadır (Şekil 23). Arıza sayılarını azalması bölgelere verilen su miktarının azalması demektir. Diğer bir değişle sistemin su kaybının azalmasıdır.

Su dağıtım sistemlerinde su kaybı ile mücadelede yüzeye çıkan arızalardan ziyade yüzeye çıkmayan arızaların tespiti büyük önem arz etmektedir. Yüzeye çıkmayan arızaların tespitinde İAB'lerin etkin bir şekilde takip edilerek minimum gece debisinin değişimi durumunda akustik dinleme yöntemiyle bu arızaların bulunması verimliliği artırıcı önemli bir yöntemdir. Bu yolla bulunan her bir arızanın meydana getirdiği su kaybını teorik olarak hesaplamak mümkün olamamaktadır. Ancak hesaplana bilen arızalardan yapılan çalışmalar ile ilgili örnek bir durum Tablo 1'de görülmektedir.

Bu çalışmada su kayıplarının azaltılması sağlanarak kayıp kaçak oranlarının denetimi ve önlenmesi sağlanmıştır. Böylelikle su yönetimindeki aksaklıkların ekonomik açıdan bir kayıp teşkil etmesinin de önüne geçilmiştir. İAB'lerin etkin yönetilmesi sonucunda sistem basınc1 7.5 bardan 3-5 bar aralığına düşürülmüştür. Ayrıca sistemde oluşan arızalarda \%55'lik bir düşüş olduğu görülmüştür. Yüzeye çıkmayan arızalara zamanında müdahale edilmesi ile (sadece hesaplanabile arıalar göz önüne alıdığında) yaklaşık \%7'lik su kaybı önlenmiştir ve bu durum yapılan çalışmanın ekonomik olarak katkısını göstermektedir.

Tablo 1. IBA 'ların Etkin Yönetilmesi İle Kazanılan Su

\begin{tabular}{|c|c|c|c|c|}
\hline İAB & \multicolumn{2}{|c|}{2018} & \multicolumn{2}{|c|}{2019} \\
\hline $\begin{array}{l}\text { Ölçüm } \\
\text { Bölgesi }\end{array}$ & $\begin{array}{c}\text { Kazanılan } \\
\text { Su }\end{array}$ & Yıllık Kazanç & $\begin{array}{c}\text { Kazanılan } \\
\text { Su }\end{array}$ & Yıllık Kazanç \\
\hline Yazlık & & & $230 \mathrm{~m}^{3} / \mathrm{sa}$ & $2.014 .800 \mathrm{~m}^{3} / \mathrm{y} 1 \mathrm{l}$ \\
\hline Eski Reji & $43.2 \mathrm{~m}^{3} / \mathrm{sa}$ & $378.432 \mathrm{~m}^{3} / \mathrm{y} 1 \mathrm{l}$ & $64.8 \mathrm{~m}^{3} / \mathrm{sa}$ & $567.648 \mathrm{~m}^{3} / \mathrm{y} 1 \mathrm{l}$ \\
\hline Şeker & $64.8 \mathrm{~m}^{3} / \mathrm{sa}$ & $567.648 \mathrm{~m}^{3} / \mathrm{y} 1 \mathrm{l}$ & & \\
\hline Hizırtepe & $28.8 \mathrm{~m}^{3} / \mathrm{sa}$ & $252.288 \mathrm{~m}^{3} / \mathrm{y} 11$ & $165.6 \mathrm{~m}^{3} / \mathrm{sa}$ & $1.450 .656 \mathrm{~m}^{3} / \mathrm{y} 1$ \\
\hline Maltepe & $18 \mathrm{~m}^{3} / \mathrm{sa}$ & $157.680 \mathrm{~m}^{3} / \mathrm{y} 1 \mathrm{l}$ & & \\
\hline Dibektaş & $72 \mathrm{~m}^{3} / \mathrm{sa}$ & $630.720 \mathrm{~m}^{3} / \mathrm{y} 1 \mathrm{l}$ & $90 \mathrm{~m}^{3} / \mathrm{sa}$ & $788,400 \mathrm{~m}^{3} / \mathrm{y} 1 \mathrm{l}$ \\
\hline İhsaniye & $64.8 \mathrm{~m}^{3} / \mathrm{sa}$ & $567.648 \mathrm{~m}^{3} / \mathrm{y} 1 \mathrm{l}$ & & \\
\hline Mithatpaşa & $25.2 \mathrm{~m}^{3} / \mathrm{sa}$ & $220.757 \mathrm{~m}^{3} / \mathrm{y} 1 \mathrm{l}$ & $18 \mathrm{~m}^{3} / \mathrm{sa}$ & $157.680 \mathrm{~m}^{3} / \mathrm{y} 1 \mathrm{l}$ \\
\hline Yenicami & $18 \mathrm{~m}^{3} / \mathrm{sa}$ & $157.680 \mathrm{~m}^{3} / \mathrm{y} 1 \mathrm{l}$ & & \\
\hline Tekeler & $75.6 \mathrm{~m}^{3} / \mathrm{sa}$ & $662.256 \mathrm{~m}^{3} / \mathrm{y} 1 \mathrm{l}$ & & \\
\hline $\begin{array}{c}\text { Gima } \\
\text { Kavşağ1 }\end{array}$ & & & $18 \mathrm{~m}^{3} / \mathrm{sa}$ & $157.680 \mathrm{~m}^{3} / \mathrm{y}_{1} \mathrm{l}$ \\
\hline TOPLAM & $410.4 \mathrm{~m}^{3} / \mathrm{sa}$ & $\begin{array}{c}3.595 .104 \\
\mathrm{~m}^{3} / \mathrm{yll}\end{array}$ & $586.4 \mathrm{~m}^{3} / \mathrm{sa}$ & $5.136 .840 \mathrm{~m}^{3} / \mathrm{yl}$ \\
\hline
\end{tabular}

\section{Kaynaklar}

[1] Abu-Mahfouz, A. M. (2016). Real-time dynamic hydraulic model for potable water loss reduction. Procedia Engineering, 154(7), 99- 106.

[2] Araujo, L. S. (2006). Pressure control for leakage minimisation in water distribution systems management. Water Resources Management, 20, 133-149,

[3] Ates, S. (2016). Hydraulic modelling of closed pipes in loop equations of water distribution networks. Applied Mathematical Modelling, 40, 966-983.

[4] Choi Y.J., A. J. (2014). Best Management Practices For Water Loss Control İn Seoul. Procedia Engineering, 1585-1593.

[5] Farley, M. \&. (2003). Losses in water distribution networks-A practitioner's guide to assessment, monitoring and control. IWA Publishing. London: 2003.

[6] Fernando G. A., A. A. (2019). "Pressure Management For Leakage Reduction Using Pressure Reducing Valves, Case Study İn An Andean City. Alexandria Engineering Journal 58, 1313-1326.

[7] Fontana N., A. M. (2018). Real-Time Control Of Pressure For Leakage Reduction İnWater Distribution Network: Field Experiments. J. Water Resour. Plann. Manage 144(3), 04017096-1-04017096-12, .

[8] García V. J. Cabrera E., C. E. (August 2006). The Mınımum Night Flow Method Revisited. 8th Annual Water Distribution Systems Analysis Symposium, (s. 27-30,). Cincinnati, Ohio, USA,

[9] Giustolisi, O. S. (2008). Pressure-driven demand and leakage simulation for water distribution networks. Journal of Hydraulic Engineering, 134(5), 626-635.

[10] Hussein M., Y. K. (2017). Effects Of Number Of Connections And Pipe Length To The Water Losses In Melaka. Jurnal Teknologi (Sciences \& Engineering) 79:3, 45-59.

[11] Jaber M. A. Alkasseh, M. N. (2013). Applying Minimum Night Flow to Estimate Water Loss Using Statistical Modeling: A Case Study in Kinta Valley. Water Resour Manage, 27, 1439-1455.

[12] Kanakoudis V., G. K. (2014). Applying Pressure Management to Reduce Water Losses in Two Greek cities' WDSs: Expectations, Problems, Results and Revisions. Procedia Engineering 89, 318 - 325.

[13] Kara S., K. I. (2015). Real time monitoring and control in water distribution systems for improving operational efficiency. Desalination and Water Treatment, 1-14.

[14] Karadirek, İ. E. (2016). Urban Water Losses Management In Turkey: The Legislation And Challenges. Anadolu University Journal of Science and Technology A-Applied Sciences and Engineering, $572-584$

[15] Karathanasia I, P. C. (2016). Development of a leakage control system at the water supply network of the city of Patras. , Procedia Engineering 162, 553 - 558,

[16] Kazeem B. A., Y. H. (2018). Pressure Management Strategies for Water Loss Reduction in Large-Scale Water Piping Networks: A Review. Advances in Hydroinformatics, Springer Water, 465-480.

[17] Lambert, A. (2000). What do we know about pressure: Leakage relationship in distribution systems? Brno: IWA, Czech Rep: System Approach to Leakage Control and Water Distribution Management.

[18] May, J. ( 1994). Leakage, pressure and control. BICS International Conference on Leakage Control. London: BICS. 
[19] Muhammetoğlu A, M. H. ( 2018). Management of Water Losses in Water Supply and Distribution Networks in Turkey. Turkısh Journal Of Water Science \& Management ,anuary February - March - April - May - June / Volume.

[20] Muhammetoğlu A., M. H. (2018). Management Of Water Losses İn Water Supply And Distribution Networks İn Turkey. Turkish Journal Of Water Science \& Management, Volume 2, Issue 1, 58 - 75.

[21] Samir N., K. R. (2017). Pressure control for minimizing leakage in water distribution systems. Alexandria Engineering Journal 56, 601-612.

[22] Thornton, J. \&. (2005). Progress in practical prediction of pressure: Leakage, pressure: burst frequency and pressure: consumption relationships. Proceedings of the IWA Special Conference, Leakage 05. Nova Scotia: IWA.

[23] Thornton, J. \&. (2007). Pressure management extends infrastructure life and reduce un-necessary energy cost. Proceedings of the IWA Special Conference on Water Loss (s. 511-521). Bucharest, Romania, : IWA.

[24] Wu, Z. Y. (2011). Water loss reduction (1 b.). USA: Bentley Institute Press. 